\title{
Prototipe Data Logging Monitoring System Untuk Konversi Energi Panel Surya Polycrystalline 100 Wp Berbasis Arduino Uno
}

\author{
Welly Yandi ${ }^{1}$ \\ ${ }^{1}$ Jurussan Teknik Elektro, Fakultas Teknik, Universitas Bangka Belitung \\ Email : wellyyandi.koto@gmail.com
}

\begin{abstract}
Data logger monitoring system is a tool that functions to monitor the output of solar panels in the form of voltage and current based on time and temperature. This tool uses Arduino Uno as a microcontroller to monitor or process data generated by solar panels. The sensors used are voltage sensors, current sensors and temperature sensors. The resulting data will automatically be saved on the SD Card. Data generated and stored on the SD Card will be changed using the PLX-DAQ application so that it can be read and displayed in tabular and graphical form. Meanwhile, the solar panels used in this study have a capacity of $100 \mathrm{Wp}$. In order to obtain the maximum current, a load of 6 Watt is used. Meanwhile, the battery capacity used is $5 \mathrm{Ah}$. The time generated during the battery charging process compared with the power produced by solar panels is 4.43 hours. The result, in a state of a full battery can supply electrical energy for 10 hours with a load of 6 Watt.
\end{abstract}

Keywords : Arduino Uno, Data Logger Monitoring System, Solar Panel

\section{INTISARI}

Data logging monitoring system merupakan sebuah alat yang berfungsi untuk memantau hasil keluaran panel surya berupa tegangan dan arus berdasarkan waktu dan suhu. Alat ini menggunakan Arduino Uno sebagai mikrokontroler untuk memantau atau memproses data yang dihasilkan panel surya. Sensor yang digunakan adalah sensor tegangan, sensor arus dan sensor suhu. Data yang dihasikan akan secara otomatis tersimpan pada SD Card. Data yang dihasilkan dan disimpan pada $S D$ Card akan diubah menggunakan aplikasi PLX-DAQ agar dapat dibaca dan ditampilkan dalam bentuk tabel dan grafik. Sementara, Panel surya yang digunakan dalam penelitian ini memiliki kapasitas sebesar $100 \mathrm{Wp}$. Agar diperoleh arus maksimal maka digunakan beban sebesar 6 Watt. Sedangkan, kapasitas aki yang digunakan adalah 5 Ah. Waktu yang dihasilkan selama proses pengecasan aki dibandingkan dengan daya yang dihasilkan oleh panel surya adalah 4,43 jam. Hasilnya, dalam keadaan aki penuh dapat menyuplai energi listrik selama 10 jam dengan beban 6 Watt.

Kata kunci: Arduino Uno, Data Logging Monitoring System, Panel Surya

\section{PENDAHULUAN}

Energi listrik merupakan kebutuhan utama manusia saat ini. Tanpa energi listrik semua kegiatan jadi terhalang dan tidak bisa berjalan baik. Pembangkitan energi listrik terus dikembangkan demi terpenuhinya kebutuhan manusia. Berbagai macam cara yang dilakukan dalam meningkatkan ketersediaan energi listrik[1]. Salah satunya dengan memanfaatkan sebuah produk yaitu panel surya yang memiliki kemampuan membangkitkan energi listrik dan memanfaatkan cahaya matahari sebagai sumber utamanya[2].
Panel surya memiliki berbagai macam kapasitas sesuai dengan ukuran fisiknya. Data spesifikasi tegangan, arus dan berat pun sudah ditampilkan pada bagian merk panel surya tersebut. Akan tetapi, energi listrik yang dibangkitkan oleh panel surya tidak sesuai dengan kemampuan yang tertera[3].

Kemampuan panel surya sesungguhnya akan dihasilkan ketika digunakan dengan parameter pengukuran yang baik. Untuk memastikan hasil pengukuran yang dihasilkan oleh panel surya tadi sesuai dengan yang diinginkan, bisa dilakukan pengecekan secara realtime, maka dibuatlah sebuah data logging monitoring system [4]. Alat ini 
Jurnal ECOTIPE, Volume 7, No.1, April 2020, Hal. 55-60

p-ISSN 2355-5068, e-ISSN 2622-4852

Akreditasi Kemenristekdikti (SINTA 4), SK. No.10/E/KPT/2019

DOI: 10.33019/ecotipe.v7i1.1486

berguna untuk merekap keluaran yang dihasilkan oleh panel surya secara realtime sehingga dapat dibandingkan antara kemampuan terukur dengan kapasitas tertera. Alat ini menggunakan sebuah mikrokontroler Arduino Uno dan ditambah beberapa komponen pendukung seperti sensor tegangan dan serta sensor arus[5].

Teknik pemantauan yang digunakan pada penelitian ini menggunakan data akuisisi PLXDAQ yang mampu menampilkan data dan grafik pengukuran secara realtime tanpa harus mematikan board Arduino yang digunakan sebagai data logger. Penerapan teknik pemantauan ini dapat menghemat waktu pengolahan data secara signifikan.

Data keluaran panel surya diakuisisi oleh PLX- DAQ yang dapat diintegrasikan langsung ke Microsoft Excel. Parameter keluaran panel surya yaitu arus dan tegangan diperoleh dari hasil pembacaan sensor arus dan tegangan. Hasil pembacaan dari kedua sensor tersebut kemudian ditransmisikan ke mikrokontroler Arduino yang digunakan untuk mengendalikan pembacaan sensor-sensor tersebut dan mengatur transmisinya ke sistem akuisisi data di komputer. Selama proses pencatatan, data yang diperoleh langsung disimpan, diplot, dan dianalisis di dalam Spreadsheet Excel secara realtime[4].

\section{METODE PENELITIAN}

Perancangan alat dibagi atas dua bagian, yaitu perancangan rangkaian elektronik dan perancangan program pencatat data. Perancangan rangkaian elektronik terdiri atas pemilihan komponen dan spesifikasi dan skema rangkaian. Perancangan program pencatat data merupakan pembuatan rancangan data logging pada alat yang dirancang melalui Arduino UNO[6]. Program data logging ini dirancang dengan IDE Arduino. Keseluruhan desain perancangan kemudian dianalisis dan ditinjau ketersediaan masingmasing komponen yang ada di pasaran[7].

Tegangan yang dihasilkan oleh panel surya akan dikirimkan ke relay control. Relay control akan membagi tegangan menuju baterai (aki) dan beban, arus dan tegangan dari beban akan dibaca oleh sensor arus dan sensor tegangan yang terhubung ke data logging shield. Data logging shield yang juga terhubung dengan Arduino akan menyimpan data besaran arus dan tegangan dalam interval waktu yang telah ditentukan. Data ini bisa dilihat di PC yang telah terhubung dengan Arduino. data ini kemudian kembali dimasukkan ke dalam program PLX DAQ untuk diolah menjadi grafik monitoring yang dibutuhkan. Blok diagram rancangan alat ini terlihat pada Gambar 1.

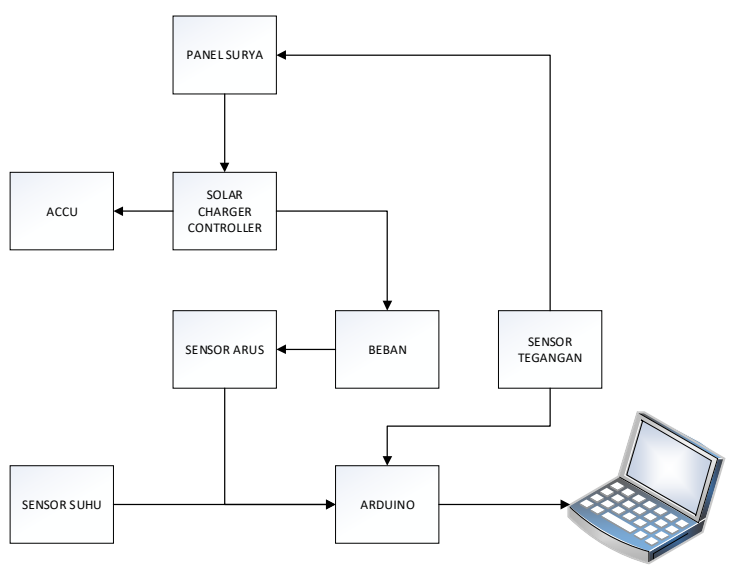

Gambar 1. Rancangan alat

Gambar 1 di atas menggambarkan pemakaian beberapa sensor agar dapat diperoleh data yang diinginkan. Sensor yang digunakan adalah sensor tegangan, sensor arus dan sensor suhu. Sensor tegangan yang digunakan adalah alat yang akan membaca tegangan yang ada pada keluaran panel surya dengan konsep kerja membagi tegangan. Tegangan yang akan dimasukkan dari Arduino pada sensor ini adalah 5 Volt. Rangkaian pembagi tegangan dapat dilihat pada Gambar 2. Sedangkan, rangkaian sensor tegangan dapat dilihat pada Gambar 3.

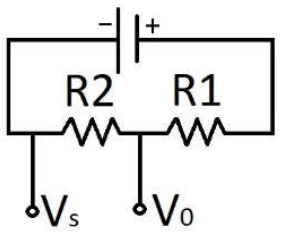

Gambar 2. Rangkaian pembagi tegangan 


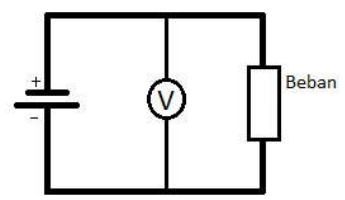

Gambar 3. Rangkaian sensor tegangan

Sensor arus yang digunakan adalah tipe ACS7712. Pembacaan arus yang dihasilkan oleh panel surya akan lebih akurat dengan menggunakan sensor tersebut. Rangkaian sensor arus dapat dilihat pada Gambar 4.

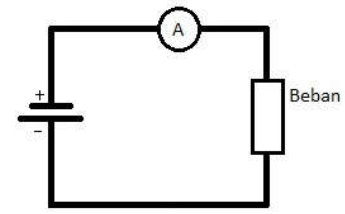

Gambar 4. Rangkaian sensor arus

Sensor suhu yang digunakan adalah tipe LM35 yang akan mengubah besaran suhu menjadi besaran listrik dalam bentuk tegangan. Besaran tegangan yang dihasilkan oleh LM35 akan dibaca Arduino dan dikeluarkan dalam bentuk data. Rangkaian sensor suhu dapat dilihat pada Gambar 5.

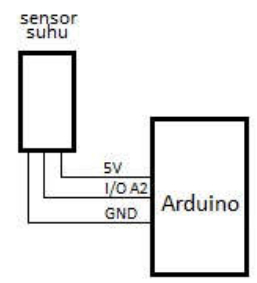

Gambar 5. Rangkaian sensor suhu LM35

Semua data yang dihasilkan kemudian diolah menjadi data excel dengan keluaran grafik menggunakan software PLX-DAQ. Dari seluruh data yang dihasilkan dapat dilihat secara terperinci teganggan, arus, suhu dan daya berdasarkan waktu sehingga dapat disimpulkan hasil dari pengukuran panel surya. Secara keseluruhan wiring diagram alat dapat dilihat pada Gambar 6.

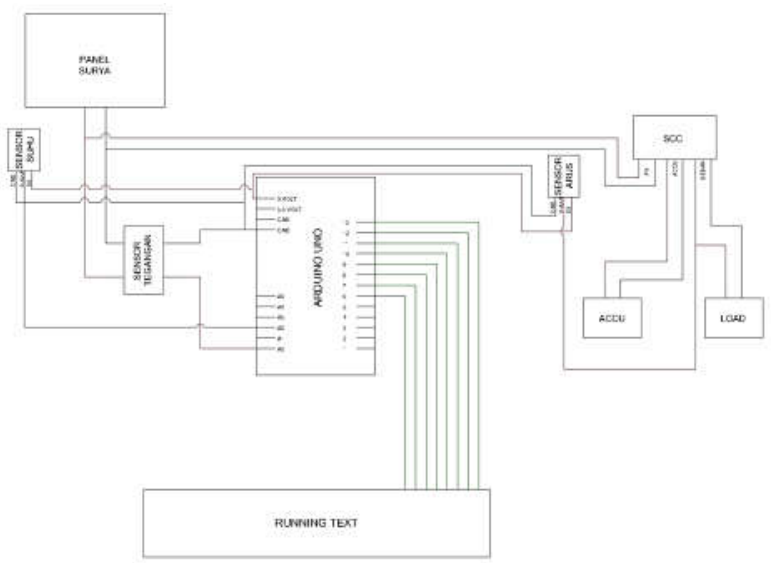

Gambar 6. Wiring diagram alat keseluruhan

\section{HASIL PENELITIAN DAN PEMBAHASAN}

Sistem pemantauan yang dirancang bekerja dengan tegangan input yang diambil dari baterai (aki) 12 Volt. Tegangan input Arduino hanya bisa menerima tegangan paling besar 5 Volt, untuk itu tegangan dari baterai (aki) diperkecil menjadi 5 Volt dengan bantuan IC 7805 sehingga tegangan 12 Volt dari baterai (aki) akan turun hingga sebesar 5 Volt. Sensor tegangan akan membaca keluaran tegangan dari panel surya. Sensor suhu diletakkan di panel surya untuk membaca suhu dari panel surya. Sensor arus diprogram untuk membaca arus yang mengalir pada beban. Panel surya yang digunakan memiliki kapasitas $100 \mathrm{Wp}$. Seluruh data yang dibaca akan ditampilkan pada LCD yang telah disiapkan. Realisasi perancangan sistem pemantauan panel surya berbasis Arduino ini dapat dilihat pada Gambar 7.

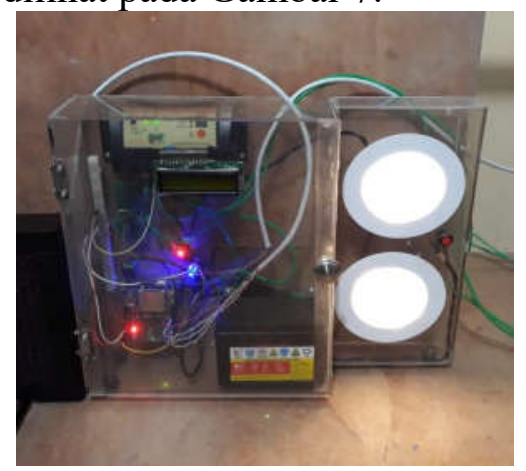

Gambar 7. Prototipe data logger system untuk panel surya 
Jurnal ECOTIPE, Volume 7, No.1, April 2020, Hal. 55-60

p-ISSN 2355-5068, e-ISSN 2622-4852

Akreditasi Kemenristekdikti (SINTA 4), SK. No.10/E/KPT/2019

DOI: 10.33019/ecotipe.v7i1.1486

Pengujian rangkaian seosor tegangan menggunakan mikrokontroler Arduino Uno, LCD dan Voltmeter. Pengujian dilakukan dengan memprogram mikrokontroler untuk memproses nilai analog yang dibaca sensor tegangan, dimana nilai analog tersebut diubah ke bentuk digital agar nilai tegangan bisa ditampilkan pada layar LCD. Nilai tegangan yang ditampilkan pada LCD kemudian dibandingkan dengan nilai tegangan yang dibaca menggunakan alat ukur Voltmeter. Perbandingan hasil pengujian sensor tegangan dengan alat ukur Voltmeter dapat dilihat pada Tabel 1.

Tabel 1. Perbandingan pembacaan sensor tegangan dengan voltmeter

\begin{tabular}{|c|c|c|c|}
\hline \multirow{2}{*}{ Sumber } & \multicolumn{2}{|c|}{ Hasil Pengukuran } & \multirow{2}{*}{$\begin{array}{c}\text { Persentase } \\
\frac{\text { nilai } \text { max }- \text { nilai } \text { min }}{\text { nilai } \text { max }}\end{array} \times 100 \%$} \\
\hline & Sensor & Voltmeter & \\
\hline $\begin{array}{l}\text { Panel } \\
\text { surya }\end{array}$ & 18,84 & 19,25 & $2.12 \%$ \\
\hline 5 Volt & 4,25 & 5.02 & $15.33 \%$ \\
\hline 7.5 volt & 6,79 & 7,52 & $9.70 \%$ \\
\hline 9 Volt & 8,11 & 9,04 & $10.28 \%$ \\
\hline 12 Volt & 11,00 & 11,74 & $6.30 \%$ \\
\hline
\end{tabular}

Pengujian rangkaian sensor arus menggunakan mikrokontroler Arduino Uno, LCD dan alat ukur Amperemeter. Langkah pengujian dilakukan dengan memprogram mikorokontroler Arduino Uno untuk memproses nilai analog yang dibaca sensor arus, dimana nilai analog tersebut dikonversi ke bentuk digital sehingga dapat ditampilkan pada layar LCD. Nilai arus yang ditampilkan di LCD kemudian dibandingkan dengan alat ukur Ampere meter. Perbandingan hasil pengujian sensor arus dengan alat ukur Amperemeter dapat dilihat pada Tabel 2.

Tabel 2. Perbandingan pembacaan sensor arus dengan Ampere meter

\begin{tabular}{ccccc}
\hline \multirow{2}{*}{ No } & Sumber & Beban & Sensor & $\begin{array}{c}\text { Ampere } \\
\text { meter }\end{array}$ \\
\hline 1 & 5 volt & $100 \Omega$ & 40,63 & 47,3 \\
\hline 2 & 12 volt & $100 \Omega$ & 82,95 & 117,6 \\
\hline
\end{tabular}

Perbedaan pembacaan tegangan dan arus menggunakan sensor dan alat ukur dikarenakan adanya perbedaan sensitifitas pengukuran keduanya. Pengambilan data keseluruhan sistem pemantauan dilakukan dari jam 06.00 WIB sampai dengan 19.00 WIB. Pengambilan data dilakukan secara langsung dan data yang diperoleh disimpan pada micro $S D$. Data keseluruhan yang diperoleh dari pemantauan dapat dilihat pada Tabel 3.

Tabel 3. Data hasil pemantauan tegangan, arus dan suhu berdasarkan waktu

\begin{tabular}{cccc}
\hline Jam & $\begin{array}{c}\text { Tegangan } \\
(\text { Volt) }\end{array}$ & $\begin{array}{c}\text { Arus } \\
(\mathbf{m A})\end{array}$ & Suhu $\left({ }^{\circ} \mathbf{C}\right)$ \\
\hline 6.00 & 2,12 & 0,636 & 17 \\
\hline 6.30 & 16,54 & 4,962 & 16 \\
\hline 7.00 & 18,84 & 5,652 & 16,62 \\
\hline 7.30 & 19,13 & 5,739 & 29,19 \\
\hline 8.00 & 19,18 & 5,754 & 33,31 \\
\hline 8.30 & 19,23 & 5,769 & 34,63 \\
\hline 9.00 & 19,23 & 5,769 & 35,13 \\
\hline 9.30 & 19,13 & 5,739 & 36,88 \\
\hline 10.00 & 19,38 & 5,814 & 34,06 \\
\hline 10.30 & 19,18 & 5,754 & 37,13 \\
\hline 11.00 & 18,74 & 5,622 & 38,81 \\
\hline 11.30 & 17,96 & 5,388 & 36,13 \\
\hline 12.00 & 18,45 & 5,535 & 34,75 \\
\hline 12.30 & 19,18 & 5,754 & 40 \\
\hline 13.00 & 18,79 & 5,637 & 41,06 \\
\hline 13.30 & 18,94 & 5,682 & 42,75 \\
\hline 14.00 & 19,13 & 5,739 & 40,69 \\
\hline 14.30 & 18,99 & 5,697 & 41,63 \\
\hline 15.00 & 19,33 & 5,799 & 38,88 \\
\hline 15.30 & 19,28 & 5,784 & 36,63 \\
\hline 16.00 & 19,18 & 5,754 & 36,75 \\
\hline 16.30 & 19,13 & 5,739 & 36,19 \\
\hline 17.00 & 18,94 & 5,682 & 34,75 \\
\hline 17.30 & 18,64 & 5,592 & 32,56 \\
\hline 18.00 & 16,93 & 5,079 & 26 \\
\hline 18.30 & 13,71 & 4,113 & 22,06 \\
\hline 19.00 & 1 & 0,3 & 21,12 \\
\hline & & & \\
\hline
\end{tabular}

Dari Tabel 3 dapat dilihat pada saat matahari mulai terbit, tegangan panel surya sudah mulai meningkat ke nilai 16 Volt yang kemudian stabil antara 16 hingga 19 Volt hingga pukul 18.30. Tegangan ini dapat diatur kembali dengan solar charger controller sesuai dengan tegangan baterai (aki) yang digunakan. Lama pemakaian baterai 
Jurnal ECOTIPE, Volume 7, No.1, April 2020, Hal. 55-60

p-ISSN 2355-5068, e-ISSN 2622-4852

Akreditasi Kemenristekdikti (SINTA 4), SK. No.10/E/KPT/2019

DOI: 10.33019/ecotipe.v7i1.1486

(aki) dapat dihitung dengan cara menghitung arus yang dibutuhkan beban terlebih dahulu, yaitu:

Arus dari beban baterai (aki)

$$
I_{\text {load }}=\frac{P}{V_{\text {accu }}}
$$

Lama pemakaian baterai (aki)

dimana,

$$
T_{\text {load }}=\frac{I_{\text {accu }}}{I_{\text {load }}}
$$

$I_{\text {load }}=$ arus yang mengalir ke beban (Ampere)

$V_{a c c u}=$ Tegangan baterai/aki (Volt)

$I_{\text {accu }}=$ kapasitas arus baterai/aki (Ampere)

$T_{\text {load }}=$ lama baterai/aki untuk dapat digunakan (Jam)

Beban yang digunakan dalam rancangan ini adalah dua buah lampu LED dengan daya totalnya adalah 6 Watt dan tegangan baterai (aki) adalah sebesar 12 Volt, maka,

$$
\text { Arus dibutuhkan beban }=\frac{6 \mathrm{Watt}}{12 \mathrm{Volt}}=0.5 \mathrm{~A}
$$

dan lama baterai (aki) untuk dapat digunakan untuk rancangan ini adalah,

$$
\text { Lama pemakaian baterai }=\frac{5 \mathrm{Ah}}{0.5 \mathrm{~A}}=10 \mathrm{jam}
$$

Jadi baterai (aki) bisa mengalirkan arus untuk beban yang dipakai di dalam rancangan ini sebesar 10 Jam. Sedangkan lama pengisian baterai (aki) saat tegangan baterai (aki) adalah:

$$
\begin{gathered}
\text { Arus pengisian }=\frac{\text { Kapasitas baterai }}{\text { Waktu pengisian baterai }} \\
1.15 \mathrm{~A}=\frac{5 \mathrm{Ah}}{\text { Waktu pengisian baterai }} \\
\text { Waktu pengisian baterai }=\frac{5 \mathrm{Ah}}{1.15 \mathrm{~A}} \\
\text { Waktu pengisian baterai }=4.437 \mathrm{jam}
\end{gathered}
$$

Grafik pemantauan tegangan, arus dan suhu berdasarkan suhu dapat dilihat pada Gambar 8 .

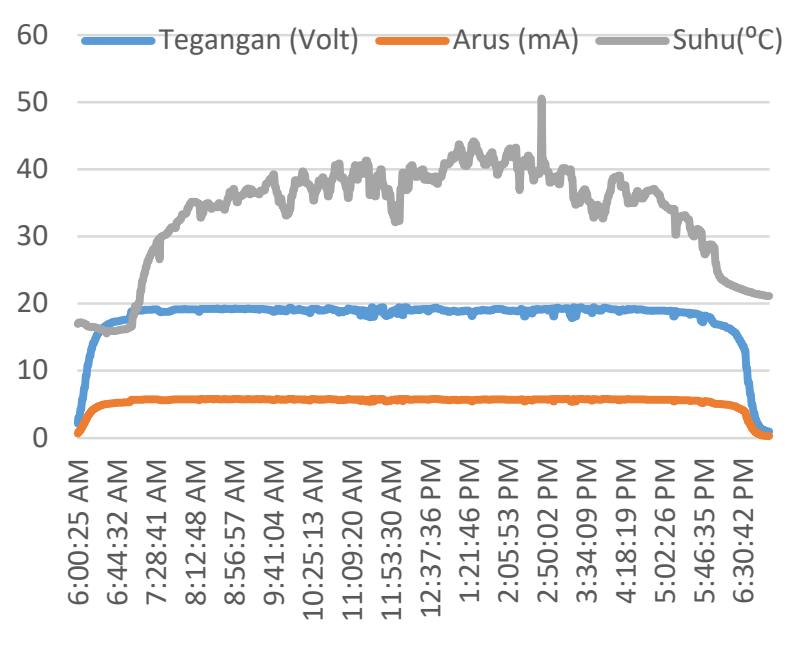

Gambar 8. Grafik data pemantauan tegangan, arus, dan suhu

\section{KESIMPULAN}

Data logging monitoring system yang digunakan dapat membaca keluaraan dari panel surya secara realtime dengan waktu yang berupa data tegangan, arus, dan suhu. Data yang dihasilkan akan lebih akurat dan mudah dibaca karena dilakukan pengukuran dan pengambilan data secara realtime. Data diolah dengan aplikasi PLX-DAQ agar data dapat dilihat dan dianalisis menggunakan tabel dan grafik. Data logging monitoring system ini tidak hanya untuk sebagai alat pemantauan konversi energi listrik dari panel surya, akan tetapi juga bisa pada memantau konversi energi listrik dari pembangkit lainnya.

\section{DAFTAR PUSTAKA}

[1] A. Febrianto, W. Sunanda, and R. F. Gusa, "Penerangan Jalan Umum Tenaga Surya: Studi Kasus di Kota Pangkalpinang," $J$. Presipitasi Media Komun. dan Pengemb. Tek. Lingkung., vol. 16, no. 2, p. 76, 2019.

[2] I. Kholiq, "Pemanfaatan energi alternatif sebagai energi terbarukan untuk mendukung subtitusi bbm," J. IPTEK, vol. 19, pp. 75-91, 2015. 
Jurnal ECOTIPE, Volume 7, No.1, April 2020, Hal. 55-60

p-ISSN 2355-5068, e-ISSN 2622-4852

Akreditasi Kemenristekdikti (SINTA 4), SK. No.10/E/KPT/2019

DOI: 10.33019/ecotipe.v7i1.1486

[3] E. Liun and Sunardi, "Perbandingan Harga Energi Dari Sumber Energi Baru Terbarukan Dan Fosil," J. Pengemb. Energi Nukl., vol. 16, no. March, pp. 119-130, 2014.

[4] W. Yandi, S. Syafii, and A. B. Pulungan, "Tracker Tiga Posisi Panel Surya untuk Peningkatan Konversi Energi dengan Catu Daya Rendah," J. Nas. Tek. Elektro, vol. 6, no. 3, p. 159, 2017.

[5] Syafii and R. Nazir, "Performance and energy saving analysis of grid connected photovoltaic in West Sumatera," Int. J. Power Electron. Drive Syst., vol. 7, no. 4, pp. 1348-1354, 2016.

[6] Syafii, M. I. Rusydi, R. Putra, and M. H. Putra, "Real-time measurement of grid connected solar panels based on wireless sensors network," Proceeding - 2016 Int. Conf. Sustain. Energy Eng. Appl. Sustain. Energy a Better Life, ICSEEA 2016, pp. 9599, 2017.

[7] H. Satria and S. Syafii, "Sistem Monitoring Online dan Analisa Performansi PLTS Rooftop Terhubung ke Grid PLN," J. Rekayasa Elektro, vol. 14, no. 2, 2018. 